\title{
Spinal cord publishes its first protocol paper
}

\author{
Lisa A. Harvey ${ }^{1}$ \\ (c) International Spinal Cord Society 2020
}

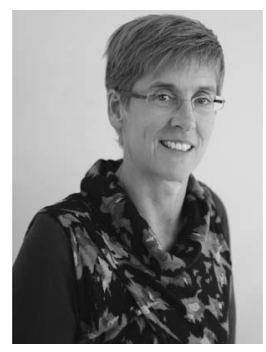

We are very pleased to publish our first protocol paper in this Edition of Spinal Cord [1]. It is the protocol for a double-blind placebo-controlled multi-center randomised controlled trial examining the effect of a multispecies probiotic on the incidence of antibiotic-associated diarrhoea in people with spinal cord injury. The trial, when completed, will no doubt be of interest to all.

There are many good reasons why we decided to start publishing protocol papers. Firstly, it helps increase awareness of large and important clinical trials that are currently underway. This in turn may prompt collaboration and avoid duplication. Secondly, it supports the scientific push to ensure that all research is conducted according to a detailed, high-quality and publically available protocol. This increases transparency and reduces bias, because it puts a stop to the file drawer problem. Thirdly, it encourages sharing of good protocols, parts of which can be used by others in their research. Lastly, and perhaps somewhat selfishly, we hope that by publishing the protocols of studies, we will in subsequent years also attract the full papers reporting on the outcomes of the completed trial.

Needless to say, Spinal Cord cannot publish the protocol of every piece of SCI research, so we need to be highly selective. We will prioritise large clinical trials that address important questions and that have solid methodology. Papers need to adhere to the SPIRIT guidelines for the reporting of trial protocols and need to clearly articulate all key design features [2]. Specifically, these papers need to specify the primary and secondary outcomes, a well- reasoned power analysis and the planned analyses. To avoid disappointment, researchers interested in publishing their protocols in SC are encouraged to make presubmission enquiries to gauge suitability.

We hope that readers will appreciate this initiative and take the opportunity to read the protocol papers we publish. This provides a very good way to reflect on trial design and to keep up to date with what is happening around the world. The protocol published in this edition provides a very high standard for all of us and should serve as a template for prospective SC authors to follow.

\section{Compliance with ethical standards}

Conflict of interest The author declares no conflict of interest.

Publisher's note Springer Nature remains neutral with regard to jurisdictional claims in published maps and institutional affiliations.

\section{References}

1. Faber WXM, Nachtegaal, J., Stolwijk-Swuste JM, AchterbergWarmer WJ, Koning CJM, Besseling - van der Vaart I. et al. Study protocol of a double-blind randomised placebo-controlled trial on the effect of a multispecies probiotic on the incidence of antibioticassociated diarrhoea in persons with spinal cord injury. Spinal Cord. 2019. https://doi.org/10.1038/s41393-019-0369-y. [Epub ahead of print]

2. An-Wen C, Jennifer MT, Peter CG, Douglas GA, Howard M, Jesse AB. et al. SPIRIT 2013 explanation and elaboration: guidance for protocols of clinical trials. BMJ. 2013;346:e7586.
Lisa A. Harvey

spinalcord@iscos.org.uk

1 University of Sydney, Sydney, Australia 